\title{
Anionic Polymerization of Methyl Methacrylate with Lithium $N$-Benzyltrimethylsilylamide
}

\author{
Tatsuki KITAYAMA ${ }^{\dagger}$ and Takehiro KITAURA \\ Department of Chemistry, Graduate School of Engineering Science, Osaka University, Toyonaka, \\ Osaka 560-8531, Japan
}

(Received February 21, 2003; Accepted March 27, 2003)

\begin{abstract}
KEY WORDS Anionic Polymerization / End-functional Polymer / Lithium Amide / Aluminum Lewis Acid / Macromonomer /
\end{abstract}

End-functional polymers have attracted much attention since they can be used for constructing more elaborated polymer chain architectures. ${ }^{1}$ Living polymerization, the concept of which was first proposed by Szwarc $^{2}$ in 1956, is one of the most promising ways to introduce a functional group at the polymer chain-end. ${ }^{3}$ Another means to obtain end-functional polymers is to polymerize a monomer with an initiator which comprises a functional group or its precursor group. 4

We have found stereospecific and living polymerization of methacrylates; isotactic-specific one with tert-butylmagnesium bromide $(t$-BuMgBr$))^{5,6}$ syndiotactic-specific one with tert-butyllithium ( $t$ $\mathrm{BuLi})$ /trialkylaluminum $\left(\mathrm{R}_{3} \mathrm{Al}\right){ }^{7,8}$ and heterotacticspecific one with $t$-BuLi and bis(2,6-di-tert-butylphenoxy)methylaluminum $\left[\mathrm{MeAl}(\mathrm{ODBP})_{2}\right]{ }^{9-17}$ More recently, we have reported that $t$ - $\mathrm{BuLi} / \mathrm{bis}(2,6$-di-tertbutylphenoxy)ethylaluminum [EtAl(ODBP $\left.)_{2}\right]$ initiating system was effective for syndiotactic-specific living polymerization of methacrylates ${ }^{13}$ and acrylates. ${ }^{18}$ In all these cases, obtained polymers have $t$-Bu group at the initiating chain-end of each polymer molecule.

Lithium dialkylamides $\left(\mathrm{R}_{2} \mathrm{NLi}\right)$ such as lithium diisopropylamide (LDA) have been known as useful anionic initiators for methacrylate polymerizations. ${ }^{19-22}$ Antoun et al. reported that LDA/lithium chloride ( $\mathrm{LiCl})$ was an effective initiating system for anionic polymerization of methyl methacrylate (MMA) in tetrahydrofuran (THF) and generated PMMA with narrow molecular weight distribution (MWD) in high initiator efficiency $(>0.9) .{ }^{20}$ The obtained polymer has the tertiary amino group at the chain end, which is less feasible for further chemical modification than primary and secondary amino groups, however. Kubo et al. reported that polymerization of MMA with $N, N^{\prime}$ -

${ }^{\dagger}$ To whom correspondence should be addressed.

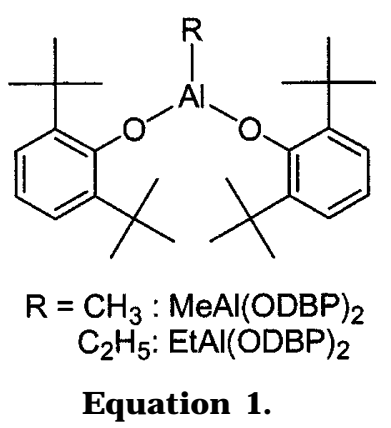

diphenylethylenediamine monolithium amide in THF afforded PMMA having secondary amino group at the initiating chain-end, though initiator efficiency and MWD of the polymer were not fully discussed. ${ }^{23}$ After introducing terminal carboxylic acid unit through the reaction with succinic anhydride, they carried out end-cyclization of the hetero-telechelic PMMA to obtain cyclic PMMA.

Lithium bis(trimethylsilyl)amide $\left(\mathrm{TMS}_{2} \mathrm{NLi}\right)$ has been known as a strong base with low nucleophilicity, and used as a mild lithiation reagent. ${ }^{24}$ Despite of its low nucleophilicity, Nagasaki et al. reported that $\mathrm{TMS}_{2} \mathrm{NLi}$ could initiate anionic polymerization of MMA. ${ }^{25}$ They declared that the polymerization provides a PMMA having a primary amino end-group after acid treatment. However, the polymer obtained had broad MWD and the initiator efficiency was low ( $c a .0 .07)$, probably owing to the inherently low nucleophilicity of $\mathrm{TMS}_{2} \mathrm{NLi}$. Antoun et $a l^{20}$ and Couper et al. ${ }^{22}$ used $\mathrm{TMS}_{2} \mathrm{NLi}$ in combination with several additives such as $\mathrm{LiCl}$ for polymerization of MMA. The initiator efficiency was still low $(<0.1)$, and MWD of the obtained polymers were relatively broad. As described above, we have found that several aluminum compounds are effective for the stereocontrol in methacrylate polymerizations. Thus, we have examined anionic polymerization of methacry- 


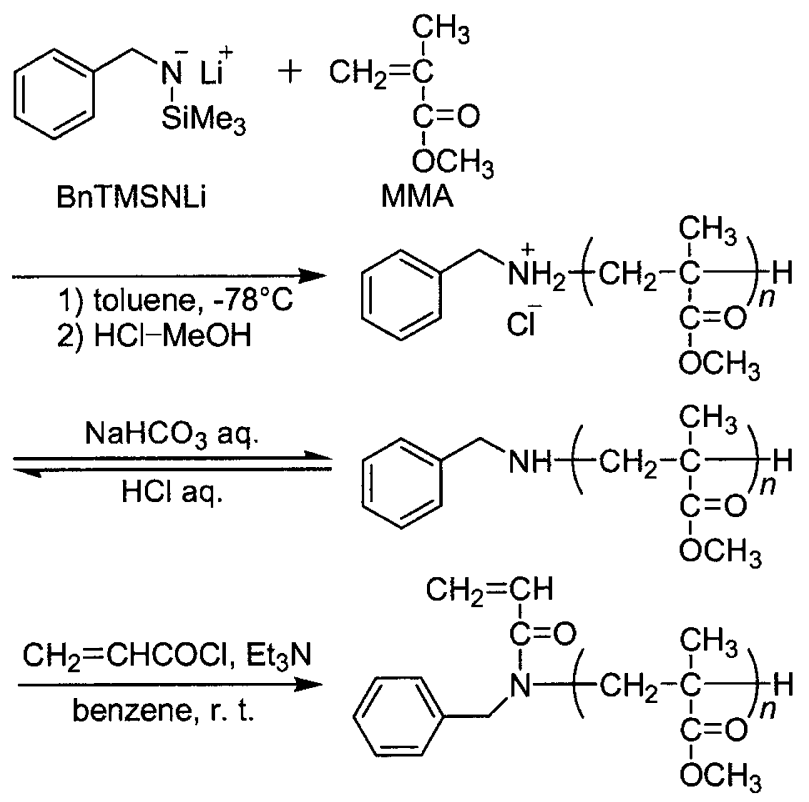

Scheme 1.

lates with $\mathrm{TMS}_{2} \mathrm{NLi} /$ tributylaluminum $\left(n-\mathrm{Bu}_{3} \mathrm{Al}\right)$ or $\mathrm{TMS}_{2} \mathrm{NLi} / \mathrm{MeAl}(\mathrm{ODBP})_{2}$ in toluene. ${ }^{26}$ The initiator efficiency was improved as compared to the polymerization with $\mathrm{TMS}_{2} \mathrm{NLi}$ alone. In the case of $\mathrm{TMS}_{2} \mathrm{NLi} / n$ $\mathrm{Bu}_{3} \mathrm{Al}$, however, the initiating chain-end of the polymer was $n$-butyl group instead of amino group to be derived from $\mathrm{TMS}_{2} \mathrm{~N}$-fragment, probably due to ate complex formation from $\mathrm{TMS}_{2} \mathrm{NLi}$ and $n-\mathrm{Bu}_{3} \mathrm{Al}$, which initiated the polymerization by releasing $n$-butyl group.

On the other hands, Yamamoto and co-workers have reported that lithium $N$-benzyltrimethylsilylamide (BnTMSNLi) reacted with methyl crotonate to generate a conjugate-addition product exclusively, while other lithium amides including LDA and $\mathrm{TMS}_{2} \mathrm{NLi}$ produced carbonyl-addition and $\gamma$-hydrogen-abstraction product in addition to the conjugate-addition product. ${ }^{27}$

The present work aims at obtaining stereoregular end-functional polymethacrylates by exploring the possibility of utilizing BnTMSNLi as a functional initiator in combination with $n-\mathrm{Bu}_{3} \mathrm{Al}, \mathrm{MeAl}(\mathrm{ODBP})_{2}$, or $\mathrm{EtAl}(\mathrm{ODBP})_{2}$ for the polymerization of methacrylates.

\section{EXPERIMENTAL}

\section{Materials}

MMA (Nacalai Tesque) and acryloyl chloride (Aldrich Co. Ltd) were purified by fractional distillation under reduced nitrogen pressure, dried over calcium dihydride $\left(\mathrm{CaH}_{2}\right)$ and vacuum-distilled just before use. Triethylamine (Nacalai Tesque) was distilled under nitrogen, dried over $\mathrm{CaH}_{2}$, and vacuum-distilled. Toluene, benzene and heptane were purified in the usual manner, mixed with a small amount of $n-\mathrm{BuLi}$ (Nacalai Tesque), and distilled under high vacuum.
$N$-Benzyltrimethylsilylamine (BnTMSNH) was prepared, according to the literature ${ }^{28}$ with a slightly modification, from benzylamine (Tokyo Chemical Industry) and trimethylsilyl chloride (1 equiv.) (Nacalai Tesque) in diethyl ether in the presence of $\mathrm{CaH}_{2}$ then fractionally distilled and dried over Molecular Sieves 4A. BnTMSNLi was prepared from BnTMSNH and $n$-BuLi ( 1 equiv.) in hexane at $0^{\circ} \mathrm{C} .{ }^{29}$ The solvent was removed under vacuum to leave a white solid, and the product was recrystallized several times by dissolving it in heptane and cooling to $-20^{\circ} \mathrm{C}$. After most of the heptane was removed by a syringe and the residual heptane was evaporated under vacuum to dryness, the solid residue was dissolved in toluene giving a clear red solution. The concentration of this solution was determined by ${ }^{1} \mathrm{HNMR}$ in toluene- $d_{8}$ at $35^{\circ} \mathrm{C}$ in combination with density measurements.

2,6-Di-tert-butylphenol was fractionally distilled and used as a heptane solution. Trimethylaluminum $\left(\mathrm{Me}_{3} \mathrm{Al}\right)$ (Aldrich Co. Ltd) and triethylaluminum $\left(\mathrm{Et}_{3} \mathrm{Al}\right)$ (Kishida Chemical) were used as received.

$\mathrm{MeAl}(\mathrm{ODBP})_{2}$ and $\mathrm{EtAl}(\mathrm{ODBP})_{2}$ were prepared according to the literatures ${ }^{11,12,30,31}$ from $\mathrm{Me}_{3} \mathrm{Al}$ or $\mathrm{Et}_{3} \mathrm{Al}$ and 2,6-di-tert-butylphenol (2 equiv.) in toluene at $0{ }^{\circ} \mathrm{C}$. Recrystallization procedures were similar to the case of BnTMSNLi and used as toluene solutions.

\section{Polymerization}

Polymerizations were carried out in glass ampoules filled with dried nitrogen passed through Molecular Sieves $4 \mathrm{~A}$ cooled at $-78^{\circ} \mathrm{C}$. Dried toluene and alkylaluminum were added to the glass ampoules, which were then cooled to polymerization temperature. Polymerization was initiated either by adding monomer after BnTMSNLi or by adding BnTMSNLi after monomer. The reactions were terminated by adding methanol containing aqueous $\mathrm{HCl}$ at the polymerization temperature. The reaction mixtures were poured into hexane, and the precipitates were collected by filtration, and then washed with hexane and $3 \mathrm{~N} \mathrm{HCl} \mathrm{sev-}$ eral times. The recovered polymers were dried under vacuum at $60^{\circ} \mathrm{C}$.

\section{Acrylation Reaction}

PMMA [number average molecular weight $\left.\left(M_{\mathrm{n}}\right)=2800, M_{\mathrm{w}} / M_{\mathrm{n}}=1.07,100 \mathrm{mg}(0.036 \mathrm{mmol})\right]$, obtained by the anionic polymerization with $\mathrm{BnTMSNLi} / n-\mathrm{Bu}_{3} \mathrm{Al}$, was dissolved in $3 \mathrm{~mL}$ dry benzene, and then acryloyl chloride $(1.11 \mathrm{mmol})$ and triethylamine $(3.0 \mathrm{mmol})$ were added in order at ambient temperature. After $20 \mathrm{~h}$, the reaction mixture was poured into hexane. The precipitate collected by filtration was dissolved in chloroform and shaken with 
Table I. Polymerization of MMA with BnTMSNLi/aluminum compounds in toluene at $-78^{\circ} \mathrm{C}$ for $24 \mathrm{~h}^{\mathrm{a}}$

\begin{tabular}{|c|c|c|c|c|c|c|c|c|}
\hline \multirow{2}{*}{ run } & \multirow{2}{*}{ Al compound } & \multicolumn{3}{|c|}{$M_{\mathrm{n}}$} & \multirow{2}{*}{$\frac{M_{\mathrm{w}}{ }^{\mathrm{d}}}{M_{\mathrm{n}}}$} & \multicolumn{3}{|c|}{ Tacticity $/ \%{ }^{\mathrm{e}}$} \\
\hline & & $\overline{\mathrm{SEC}^{\mathrm{d}}}$ & $\mathrm{NMR}^{\mathrm{e}}$ & Calcd. & & $\mathrm{mm}$ & $m r$ & $r r$ \\
\hline $1^{\mathrm{b}}$ & \multirow{2}{*}{ none } & 4200 & 4800 & \multirow{8}{*}{2600} & 6.37 & 79.6 & 16.4 & 4.0 \\
\hline $2^{\mathrm{c}}$ & & 4400 & 4800 & & 9.10 & 81.5 & 15.6 & 2.9 \\
\hline $3^{\mathrm{b}}$ & \multirow{2}{*}{$n-\mathrm{Bu}_{3} \mathrm{Al}$} & 6700 & 8600 & & 1.42 & 4.1 & 18.3 & 77.6 \\
\hline $4^{c}$ & & 2800 & 2800 & & 1.07 & 6.0 & 13.1 & 80.9 \\
\hline $5^{\mathrm{b}}$ & \multirow{2}{*}{$\mathrm{MeAl}(\mathrm{ODBP})_{2}$} & 3100 & 3300 & & 1.21 & 13.3 & 64.7 & 22.0 \\
\hline $6^{c}$ & & 3000 & 3100 & & 1.21 & 13.8 & 65.8 & 20.4 \\
\hline $7^{b-}$ & \multirow{2}{*}{$\operatorname{EtAl}(\mathrm{ODBP})_{2}$} & 2700 & 2800 & & 1.09 & 6.0 & 13.8 & 80.2 \\
\hline $8^{c}$ & & 2900 & 2900 & & 1.10 & 5.3 & 14.6 & 80.1 \\
\hline
\end{tabular}

${ }^{\text {a}}$ Toluene $10 \mathrm{~mL}$, BnTMSNLi $0.4 \mathrm{mmol}, \mathrm{Al} / \mathrm{Li}=3$, MMA $10 \mathrm{mmol}$, yield $100 \%$. ${ }^{\mathrm{b}}$ Addition order; aluminum compounds, BnTMSNLi, MMA. ${ }^{\mathrm{c} A d d i t i o n}$ order; aluminum compounds, MMA, BnTMSNLi. ${ }^{\mathrm{d}}$ Determined by SEC in THF (PMMA standards). ${ }^{\mathrm{e}}$ Determined by $400 \mathrm{MHz}{ }^{1} \mathrm{H} \mathrm{NMR}\left(\mathrm{CDCl}_{3}, 55^{\circ} \mathrm{C}\right)$.

$3 \mathrm{~N} \mathrm{HCl}$, and then the chloroform was evaporated to dryness.

\section{Measurements}

${ }^{1} \mathrm{H}$ NMR spectra were measured in chloroform- $d$ at $55^{\circ} \mathrm{C}$ on a JEOL JNM400 spectrometer operated at $400 \mathrm{MHz}$. Tacticities of PMMAs were determined from $\alpha$-methyl hydrogen signals. $M_{\mathrm{n}}$ was determined by ${ }^{1} \mathrm{H}$ NMR spectroscopic end-group analysis, by using benzylmethylene proton signal $(4.2 \mathrm{ppm})$ of the initiator fragments and methoxy methyl proton signal (3.7 ppm). $M_{\mathrm{n}}$ and molecular weight distribution (MWD) were also determined by size exclusion chromatography (SEC) using a JASCO TRI ROTAR-V chromatograph equipped with Polymer Laboratories SEC columns MIXED-C $\times 2(7.5 \mathrm{~mm}$ i.d. $\times 300 \mathrm{~mm})$ using THF as an eluent at $40^{\circ} \mathrm{C}$. SEC chromatograms were calibrated against standard PMMA samples (Shodex).

\section{RESULTS AND DISCUSSION}

Polymerization of MMA with BnTMSNLi in combination with $n-\mathrm{Bu}_{3} \mathrm{Al}, \mathrm{MeAl}(\mathrm{ODBP})_{2}$ or $\mathrm{EtAl}(\mathrm{ODBP})_{2}$ $(1 / 3)$ was conducted in toluene at $-78^{\circ} \mathrm{C}$ and the results were summarized in Table I. In the first series of experiments, the reagents were added to toluene in the following order; aluminum compounds, BnTM$\mathrm{SNLi}$, and monomer, as reported for the polymerization with $t$-BuLi/aluminum compounds. ${ }^{7-18}$ The polymerization with BnTMSNLi alone gave PMMA in a good yield but with broad MWD in low initiator efficiency (run 1). In contrast, the polymerizations with BnTMSNLi/MeAl(ODBP) $)_{2}$ (run 5) and BnTMSNLi/EtAl(ODBP) ${ }_{2}$ (run 7) afforded PMMAs which had controlled molecular weights and narrow MWDs. In the case of $\mathrm{BnTMSNLi} / n-\mathrm{Bu}_{3} \mathrm{Al}$, however, $M_{\mathrm{n}}$ was fairy larger than the expected one and the MWD was relatively broad (run 3). We anticipated that BnTMSNLi formed a complex with $n$ $\mathrm{Bu}_{3} \mathrm{Al}$ such as ate complex and lost nucleophilic addition reactivity, while $\mathrm{MeAl}(\mathrm{ODBP})_{2}$ and $\mathrm{EtAl}(\mathrm{ODBP})_{2}$ were too bulky to form such complexes at least at $-78^{\circ} \mathrm{C}$. To avoid such kind of complex formation prior to the initiation reaction, we attempted to change the addition order of the reagents as aluminum compounds, monomer and BnTMSNLi so that the initiation reaction takes place before the complex formation. The polymerizations with BnTMSNLi alone and with BnTMSNLi/MeAl(ODBP) $)_{2}$ or BnTMSNLi/EtAl(ODBP) $)_{2}$ were not affected significantly by the change of the addition order (runs 2, 6, 8). On the contrary, the addition order exerted great influence on the polymerization with $\mathrm{BnTMSNLi} / n-\mathrm{Bu}_{3} \mathrm{Al}$ (run 4). The initiator efficiency was so much improved that the $M_{\mathrm{n}}$ value became close to the calculated one and the MWD was narrower. These results support above-mentioned anticipation that BnTMSNLi forms the complex with $n-\mathrm{Bu}_{3} \mathrm{Al}$ but not with $\mathrm{MeAl}(\mathrm{ODBP})_{2}$ or $\operatorname{EtAl}(\mathrm{ODBP})_{2}$.

Figure 1a illustrates ${ }^{1} \mathrm{H}$ NMR spectrum of PMMA prepared with $\mathrm{BnTMSNLi} / n-\mathrm{Bu}_{3} \mathrm{Al}$ (Table I, run 4). Since the polymerization was terminated with $\mathrm{HCl}-$ $\mathrm{MeOH}$, it is expected that the trimethylsilyl group in the initiator fragment is easily eliminated and hydrochloride salt of PMMA with benzylamino endgroup is produced. In fact, the PMMA did not show trimethylsilyl group signal around $0 \mathrm{ppm}$, and exhibited ammonium proton signals at lower magnetic field. Aromatic and benzyl methylene proton signals, which derived from the initiator fragment, were observed around 7.6, 7.4, and $4.2 \mathrm{ppm}$, respectively. Moreover, the spectrum showed methylene proton signals of the first monomer unit, which attached to the amino end-group. $M_{\mathrm{n}}$ estimated from integral in- 


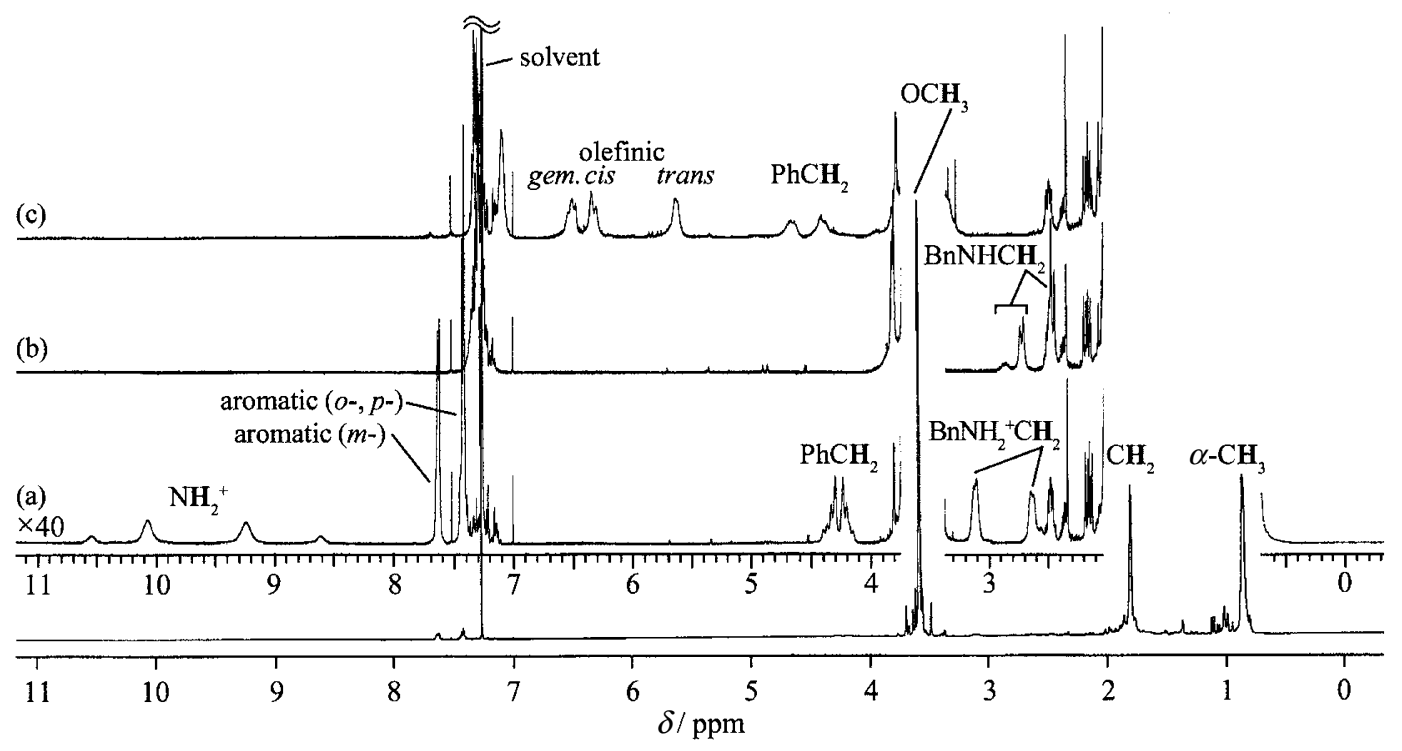

Figure 1. ${ }^{1} \mathrm{H}$ NMR spectra of PMMA $\left(\mathrm{CDCl}_{3}, 55^{\circ} \mathrm{C}\right)$. (a) $\alpha$-Benzylamino-PMMA hydrochloride salt, (b) $\alpha$-benzylamino-PMMA, (c) $\alpha$-(N-acryloylbenzylamino)-PMMA.

tensity ratio of benzyl and methoxy proton signals was close to the expected value, suggesting high initiator efficiency $(>0.9)$. The fact that the $M_{\mathrm{n}}$ estimated by ${ }^{1} \mathrm{H}$ NMR end-group assay also agreed with the value determined by SEC analysis indicates that each polymer molecule has one benzyl amino group. The polymers obtained by BnTMSNLi/MeAl(ODBP $)_{2}$ or BnTMSNLi/EtAl(ODBP) $)_{2}$ gave similar spectra. Tacticities of the produced polymers were isotactic rich $(m m \approx 80 \%)$ in the case of BnTMSNLi alone. Heterotactic rich polymers $(m r \approx 65 \%)$ were obtained with BnTMSNLi/MeAl(ODBP) $)_{2}$, and syndiotactic rich ones $(r r \approx 80 \%)$ with $\mathrm{BnTMSNLi} / n$ - $\mathrm{Bu}_{3} \mathrm{Al}$ and $\mathrm{BnTMSNLi} / \mathrm{EtAl}(\mathrm{ODBP})_{2}$. The polymerization of MMA with $t-\mathrm{BuLi} / n-\mathrm{Bu}_{3} \mathrm{Al}$ gives the polymer with higher $r r$ content $(r r>90 \%){ }^{7,8}$ Syndiotacticity of the polymers obtained in the present work was estimated relatively low, partly due to the overlap signals of monomer units at and near chain ends.

In order to confirm the existence of the amino endgroup, a chloroform solution of the polymer was shaken with aqueous $\mathrm{NaHCO}_{3}$ to convert the ammonium salt to free amine. In the ${ }^{1} \mathrm{H}$ NMR spectrum of the polymer after treatment with $\mathrm{NaHCO}_{3}$ (Figure 1b), ammonium proton signals around $10 \mathrm{ppm}$ disappeared and methylene proton signals at 3.1 and $2.6 \mathrm{ppm}$ shifted to higher field. Aromatic proton signals around 7.6 and $7.4 \mathrm{ppm}$ shifted to overlap $\mathrm{CHCl}_{3}$ signal, and benzyl methylene proton signal at $4.2 \mathrm{ppm}$ was assumed to shift to overlap methoxy signal. When this polymer was treated with aqueous $\mathrm{HCl}$, the ${ }^{1} \mathrm{H}$ NMR spectrum became identical to that in Figure 1a, which indicates the reversible protonation of amino group.

To further confirm the presence of the amino group and its feasibility of further derivatization, the PMMA was reacted with acryloyl chloride to convert the end group to $\mathrm{N}$-acryloylbenzylamino group. Figure 1c illustrates the spectrum of the obtained polymer, which demonstrates the existence of acrylamide group. $M_{\mathrm{n}}$ calculated from integrations of methoxy and olefinic protons was 2800 , which is consistent with the value of the starting polymer. Thus, it is proved that the reaction was quantitative, and that the amino end-group had high reactivity enough for quantitative conversion.

\section{REFERENCES}

1. R. Jerome, M. Henrioulle-Granville, B. Boutevin, and J. J. Robin, Prog. Polym. Sci., 16, 837 (1991).

2. M. Szwarc, Nature, 178, 1168 (1956).

3. A. Hirao and M. Hayashi, Acta Polym., 50, 219(1999).

4. H. L. Hsieh and R. P. Quirk, "Anionic Polymerization: Principles and Practical Applications", Marcel Dekker Inc., New York, N.Y., 1996.

5. K. Hatada, K. Ute, K. Tanaka, T. Kitayama, and Y. Okamoto, Polym. J., 17, 977 (1985).

6. K. Hatada, K. Ute, K. Tanaka, Y. Okamoto, and T. Kitayama, Polym. J., 18, 1837 (1986).

7. T. Kitayama, T. Shinozaki, E. Masuda, M. Yamamoto, and K. Hatada, Polym. Bull., 20, 505 (1988).

8. T. Kitayama, T. Shinozaki, T. Sakamoto, M. Yamamoto, and K. Hatada, Makromol. Chem. Suppl., 15, 167 (1989).

9. T. Kitayama, Y. Zhang, and K. Hatada, Polym. Bull., 32, 439 (1994).

10. T. Kitayama, Y. Zhang, and K. Hatada, Polym. J., 26, 868 (1994).

11. T. Kitayama, T. Hirano, and K. Hatada, Polym. J., 28, 61 (1996).

12. T. Kitayama, T. Hirano, Y. Zhang, and K. Hatada, Macromol. Symp., 107, 297 (1996). 
13. T. Kitayama, T. Hirano, and K. Hatada, Tetrahedron, 53, 15263 (1997).

14. T. Hirano, T. Kitayama, and K. Hatada, Polym. J., 30, 736 (1998).

15. T. Hirano, H. Yamaguchi, T. Kitayama, and K. Hatada, Polym. J., 30, 767 (1998).

16. T. Hirano, T. Kitayama, J. Cao, and K. Hatada, Macromolecules, 33, 1926 (2000).

17. T. Hirano, T. Kitayama, J. Cao, and K. Hatada, Polym. J., 32, 961 (2000).

18. M. Tabuchi, T. Kawauchi, T. Kitayama, and K. Hatada, Polymer, 43, 7185 (2002).

19. T. E. Long, R. A. Guistina, B. A. Schell, and J. E. McGrath, J. Polym. Sci., Part A: Polym. Chem., 32, 2425 (1994).

20. S. Antoun, Ph. Teyssie, and R. Jerome, J. Polym. Sci., Part A: Polym. Chem., 35, 3637 (1997).

21. S. Antoun, Ph. Teyssie, and R. Jerome, Macromolecules, 30, 1556 (1997).

22. S. A. Couper, R. E. Mulvey, and D. C. Sherrington, Eur. Polym. J., 34, 1877 (1998).
23. M. Kubo, H. Yamamoto, T. Uno, T. Itoh, and H. Sato, Polym Bull., 47, 25 (2001).

24. H. J. Reich and J. H. Rigby, "Handbook of Reagents for Organic Synthesis, Acidic and Basic Reagents", John Wiley \& Sons, Inc., New York, N.Y., 1999, p 221.

25. Y. Nagasaki, N. Nishizuka, and T. Tsuruta, Polym. J., 27, 959 (1995).

26. T. Kitayama, M. Satoh, T. Yabuta, T. Hirano, T. Kawauchi, T. Kitaura, unpublished work.

27. N. Asao, T. Uyehara, and Y. Yamamoto, Tetrahedron, 44, 4173 (1988).

28. D. A. Gaul, O. Just, and W. S. Rees Jr., Inorg. Chem., 39, 5648 (2000).

29. D. R. Armstrong, D. R. Baker, F. J. Craig, R. E. Mulvey, W. Clegg, and L. Horsburgh, Polyhedron, 15, 3533 (1996).

30. K. Maruoka, T. Itoh, M. Sakura, K. Konoshita, and H. Yamamoto, J. Am. Chem. Soc., 110, 3588 (1988).

31. A. P. Shreve, R. Mulhaupt, W. Fultz, J. Carabrese, W. Robbins, and S. D. Ittel, Organometallics, 7, 409 (1988). 